\title{
Current status of vertebrate diversity in anthropogenic and natural ecosystems in south-western Sri Lanka
}

\author{
S.N. Gamage ${ }^{1,2}$, D.K. Weerakoon ${ }^{2 *}$ and A. Gunawardena ${ }^{3}$ \\ ${ }^{1}$ Land Owners Restore Rainforest in Sri Lanka, Bangamukanda Estate, Pitigala. \\ ${ }^{2}$ Department of Zoology, Faculty of Science, University of Colombo, Colombo 03 \\ ${ }^{3}$ Department of Animal Science, Faculty of Agriculture, University of Ruhuna, Mapalana, Kamburupitiya.
}

\begin{abstract}
Fragmentation of natural habitats is one of the major threats to long term conservation of biodiversity in Sri Lanka. Establishing corridors to link these natural habitat patches is one of the simplest strategies that can be used to address this threat. However, it is not possible to establish forest corridors everywhere and therefore alternate strategies need to be developed. This study was undertaken to test whether agroecosystems could be used as permeable matrices to link natural habitat patches. Four sites with different land use types were selected in the south-western region of Sri Lanka, where the highest level of habitat fragmentation occurs. These four sites represent three agro-ecosystems (tea, rubber and oil palm) and a natural ecosystem. Presence of herpetofauna, birds and large mammals in these four sites were enumerated using the quadrate sampling method $(8 \times 8 \mathrm{~m})$ for herpetofauna and the line transect method for birds and mammals. At each site, sampling was carried out from September 2002 to November 2004. A total of 187 species of vertebrates were recorded from the four sites. This comprised 53 species of herpetofauna (41 species of reptiles and 12 species of amphibians), 99 species of birds and 35 species of mammals. Overall species richness (178) as well as the species richness of each of the three major taxa studied, namely, herpetofauna (51), birds (97) and mammals (30) were found to be the highest in the natural forest compared to the three agro-ecosystems. The agro-ecosystems were used by a large number of vertebrate species. However, the species assemblage in these agro-ecosystems was dominated by common species and comprised a few species that are threatened or endemic to Sri Lanka, compared to the natural forest. Therefore, it can be concluded that agro-ecosystems are important for maintaining population densities of common species. Further, this study clearly demonstrates the value of natural forests for preservation of threatened and endemic vertebrates. Since agro-ecosystems are not utilized by highly specialized threatened and endemic species, it is unlikely that this type of land use will create a permeable matrix among fragmented natural forests for such species.
\end{abstract}

Keywords: Agro-ecosystems, fragmentation, linking forest fragments, species richness.

\section{INTRODUCTION}

Until the late 1980s, biological conservation efforts were mainly focused on undisturbed natural habitats, including protected areas that cover only about $5 \%$ of the world's land area (Scherr \& Shames, 2006). However, the focus on undisturbed habitats was challenged at the dawn of this decade, where attention was called on the fact that at least two-thirds of the terrestrial environment of the planet consisted of managed ecosystems such as agricultural systems, plantation forests and human settlements (McNeely, 1995). Consequently, a large portion of the world's biological diversity coexists with humans in these man-made landscapes. Therefore, there is a greater tendency at present, to focus conservation efforts on such agricultural and forestry systems in addition to the undisturbed lands.

Sri Lanka has one of the densest human populations in Asia, especially in the Wet Zone. A burgeoning population, demand for subsistence land and a high proportion of endangered and endemic species within the Wet Zone of Sri Lanka have resulted in it being declared as a critically endangered eco-region (Brooks, et al., 2002). Internationally, Sri Lanka, together with the Western Ghats in southern India, is listed as a global hotspot for biological diversity (Myers et al., 2000; Mittermeier et al., 2005). The lowland Wet Zone of the island has been identified as having the highest incidence of biodiversity of Sri Lanka and a high percentage of endemism. However, the low land rainforest represents

${ }^{*}$ Corresponding author (devakaw@gmail.com) 
only $2.1 \%$ of the island's land area. These forests are highly fragmented and exist as separate ecosystems. Agroecosystems such as home gardens, paddy, tea, rubber, cinnamon and oil palm plantations cover a major portion of the land area in the Wet Zone, which forms unique man-made habitats with differing physical, chemical and biological properties. These habitats are frequently subjected to modification by man and therefore, the environment of these habitats is often changing whose impact on the biodiversity is little known to science. However, these man-made habitats function as an integral part of the habitats of large number of fauna and flora (Bambaradeniya et al., 2004; Gamage et al., 2007; Gamage \& Weerakoon, 2007). In agro-ecosystems, fauna and flora play a major role in maintaining the biological balance by controlling pest species (Bambaradeniya et al., 2004). The biodiversity of such agro-ecosystems is not fully assessed at present as reflected by the paucity of the literature available on this aspect. Therefore, the objective of this study was to investigate the biodiversity of three selected agro-ecosystems in the Wet Zone of Sri Lanka in relation to a natural habitat to asses their value as habitats for species as well as their ability to link natural habitat patches.

\section{METHODS AND MATERIALS}

Four sites were selected in the southwest region of the country, as the main objective of this study was to compare biodiversity in agro-ecosystems with natural ecosystems in the biodiversity rich Wet Zone of Sri Lanka.

These four sites represent three agro-eco systems (tea, rubber and oil palm) and a natural ecosystem, located in the Yakkalamulla and Akmeemana divisional secretariat divisions. The elevation ranges from $30-100$ $\mathrm{m}$ above mean sea level with a mean annual rainfall of $2510 \mathrm{~mm}$. The rain is well distributed throughout the year except for the two dry months, January and February.

The study was conducted for a period of two years from September 2002 to November 2004. Two main methods, the fixed line transect and the quadrate sampling technique, were used to document the herptofauna, birds and mammals present in the four study sites.

Herpetofauna: In each study site a standard plot of $100 \mathrm{~m} \times 100 \mathrm{~m}$ was established for sampling. In the natural forest the sampling plot was selected in the least disturbed area with no tree fall gaps. In the agroecosystems the plot was established in a well-managed area. The four corners of the plot were demarcated and a GPS reading was obtained from the center of the plot. The plots were positioned in such a way that the $\mathrm{Y}$ axis is aligned along a north-south direction and the $\mathrm{X}$ axis is aligned along the east-west direction. The plot was then subdivided into $10 \mathrm{~m} \times 10 \mathrm{~m}$ sub plots and marked with coloured tape. Eighteen sub plots were selected randomly for sampling. In each of the selected sub plots a $8 \times 8 \mathrm{~m}$ quadrate was demarcated using a polythene fence $(45 \mathrm{~cm}$ height) along the sides of the quadrate to prevent animals from escaping. Then starting from one end the entire quadrate was sampled by sorting through the leaf litter, tree trunks, branches, and also under stones and logs. Quadrate sampling was carried out from September 2003 to November 2003. In addition, line transects were also used to collect opportunistic data on herpetofauna.

Birds and mammals: Species richness of birds and mammals was assessed using the fixed line transect method. In each study site a $1 \mathrm{~km}$ x $20 \mathrm{~m}$ strip transect was established. This transect was traversed at a speed of 0.5 to $1 \mathrm{~km} / \mathrm{h}$ and the number and identity of animals observed were recorded. In each site both day and night surveys were conducted between September 2002 and November 2004. Daytime sampling was carried out between $6.30-9.00 \mathrm{am}$ and $4.00-6.00 \mathrm{pm}$. Night sampling was carried out between $7.00-10.00 \mathrm{pm}$ and $2.00-6.00 \mathrm{am}$. Headlamps were used to spot animals at night and red lights were used to reduce disturbance to animals. A total of 38 day time transects and 7 night time transects were carried out at each of the study sites.

Identification and analysis: Identification of vertebrate species was based on the most recent taxonomic keys or guides available (Corbet \& Hill, 1992; Dutta \& Manamendra-Arachchi, 1996; Manamendra-Arachchi \& Pethiyagoda, 1998; Pethiyagoda \& ManamendraArachchi, 1998; Harrison, 1999; Wickramasinghe \& Somaweera, 2003; Das \& De Silva, 2005; ManamendraArachchi \& Pethiyagoda, 2005; Meegaskumbura \& Manamendra-Arachchi, 2005). Nomenclature used in this paper is based on names given in Bambaradeniya (2006). Identification of the Global and national conservation status of species was based on IUCN (2008) and IUCN \& MENR (2007), respectively.

The indices defined below that were used to compare the vertebrate assemblages of the different habitats were based on Magurran (1998) and Southwood \& Henderson (2000).

Diversity $=\mathrm{H}^{\prime}=-\sum \mathrm{P}_{\mathrm{i}} \ln \mathrm{P}_{\mathrm{i}}\left(\mathrm{P}_{\mathrm{i}}=\mathrm{n}_{\mathrm{i}} / \mathrm{N}\right.$ (where, $\mathrm{n}_{\mathrm{i}}=$ number of individuals in $i^{\text {th }}$ species, $N=$ total number of individuals). Evenness $=\mathrm{E}=\mathrm{H}^{\prime} / \ln \mathrm{S}$ (where $\mathrm{H}^{\prime}=$ Shannon evenness measure, $\mathrm{S}=$ number of species or species richness). Dominance $=\mathrm{D}=\sum \mathrm{P}_{\mathrm{i}}^{2}$ (where, $\mathrm{P}_{\mathrm{i}}$ $\left.=\mathrm{n}_{\mathrm{i}} / \mathrm{N}\right)$. Sørensen's similarity co-efficient $\left(\mathrm{C}_{\mathrm{S}}\right)=2 \mathrm{j} /$ 
$(\mathrm{a}+\mathrm{b})$ (where, $\mathrm{a}=$ number of species in habitat $\mathrm{A}, \mathrm{b}=$ number of species in habitat $B$ and $j=$ number of species common to habitat $\mathrm{A}$ and $\mathrm{B})$.

\section{RESULTS}

\section{Herpetofaunal assemblage}

A total of 53 species of herpetofauna were recorded from the four study sites. This comprised 41 species of reptiles and 12 species of amphibians including 17 species of endemic reptiles and 6 species of endemic amphibians. Further, 4 species of threatened reptiles and 1 species of threatened amphibians were also recorded from the four sites (Table 1).

Table 1: Summary of herpetofauna recorded at the four sites. The number in parenthesis indicates the number of species restricted to that particular habitat

\begin{tabular}{lccccc}
\hline Taxonomic group & Total & Natural & Tea & Rubber & Oil palm \\
\hline Reptiles & & & & & \\
$\quad$ Number of species & 41 & $39(16)$ & 17 & 25 & 24 \\
Endemic species & 17 & $17(10)$ & 3 & 7 & 7 \\
Threatened species & 4 & $4(3)$ & 1 & 1 & 1 \\
Amphibians & & & & & \\
Number of species & 12 & $12(3)$ & 5 & 7 & 8 \\
Endemic species & 6 & $6(2)$ & 2 & 4 & 3 \\
Threatened species & 1 & 1 & 1 & 1 & 1 \\
\hline
\end{tabular}

The highest species richness (51 species) was observed in the natural forest, which included all the endemic and threatened species recorded. Further, of the 23 endemic herpetofaunal species observed, 12 were recorded only in the natural forest and most of them were recorded at low densities and thus can be considered as a rare species. Likewise of the 5 threatened species recorded, 3 were restricted to the natural habitat. Among the agroecosystems the highest species richness was recorded in the rubber and oil palm plantations (32 species each) followed by the tea plantations ( 22 species). Only a few endemic and threatened species were recorded in these three agro-ecosystems.

The density of herpetofauna recorded in the natural forest (466 animals/ ha) was much higher compared to the three agro-ecosystems. Among the agro-ecosystems, oil palm plantation had the highest herpetofaunal density (175 animals / ha) while the tea plantation had the lowest density (75 animals / ha).
The natural forest had the highest species diversity followed by plantations of rubber, oil palm and tea (Table 2). The evenness (E) was relatively high in all four sites indicating that no specific species dominated the species assemblage. This is further confirmed by low values obtained for the dominance index (D).

A pairwise comparison of the herpetofaunal assemblages between each study site showed that there is a higher degree of similarity among the three man-made ecosystems while the natural forest showed a low level of similarity to any of the three man made ecosystems (Table 3). Further, the herpetofaunal assemblages in the rubber and oil palm plantations showed a high degree of similarity.

Table 2: Species diversity, evenness, and dominance indices of the herpetofauna in the four study sites

\begin{tabular}{lllll}
\hline & \multicolumn{3}{c}{ Vegetation types } \\
& Natural & Tea & Rubber & Oil palm \\
\hline Shannon-wiener diversity & & & & \\
index (H') & 3.0096 & 2.2192 & 2.5517 & 2.5472 \\
Evenness (E) & 0.79 & 0.74 & 0.75 & 0.75 \\
Dominance (D) & 0.0772 & 0.1625 & 0.1100 & 0.1084 \\
\hline
\end{tabular}

Table 3: Pairwise comparison of the herpetofaunal assemblages in the four study sites using Sørensen similarity coefficient

\begin{tabular}{lllll}
\hline & Natural & Tea & Rubber & Oil palm \\
\hline Natural & & & & \\
Tea & 0.5135 & & & \\
Rubber & 0.7229 & 0.7925 & & \\
Oil palm & 0.7229 & 0.7925 & 0.9375 & \\
\hline
\end{tabular}

\section{Avifaunal assemblage}

A total of 99 species of birds were observed during the study period. This included 11 species of endemic birds and 5 species of threatened birds (Table 4). The highest species richness (97 species) was observed in the natural forest, which included all the endemic species and all 5 threatened species recorded. Further, 8 of the 11 endemic species and 4 of the 5 threatened species were found to be restricted to the natural forest. Among the agroecosystems the highest species richness was recorded in plantations of tea (68 species) followed by rubber (63 species) and oil palm (55 species). Of the 99 species of birds recorded 50 species were observed in all 4 study sites. 
The density of avifauna was found to be much higher ( 52 birds/ ha) in the natural forest compared to the agroecosystems. Avifaunal density in all 3 agro-ecosystems were similar with tea ( 21 birds/ ha) having the highest density and oil palm having the lowest density (17 birds / ha).

As previously mentroned the natural forest had a higher species diversity followed by rubber, tea and oil palm plantations (Table $2 \& 5$ ). A pairwise comparison of the avifaunal assemblages among study sites also showed that there is a higher degree of similarity among the 3 man-made ecosystems while the natural forest showed a low level of similarity to any of the 3 agro-ecosystems (Table 6).

Table 4: Summary of avifauna recorded at the four sites. The number in parenthesis indicates the number of species restricted to that particular habitat

\begin{tabular}{lrcccc}
\hline Category & Total & Natural & Tea & Rubber & Oil palm \\
\hline Number of species & 99 & $97(29)$ & 68 & 63 & 55 \\
Endemic species & 10 & $11(8)$ & 3 & 2 & 2 \\
Threatened species & 6 & $5(4)$ & 1 & 0 & 0 \\
\hline
\end{tabular}

Table 5: Species diversity, evenness, and dominance indices of the avifauna in the four study sites

\begin{tabular}{lllll}
\hline & \multicolumn{4}{c}{ Vegetation types } \\
& Natural & Tea & Rubber & Oil palm \\
\hline Shannon-wiener & & & & \\
diversity index (H') & 3.9272 & 3.4246 & 3.4777 & 3.3130 \\
Evenness (E) & 0.90 & 0.84 & 0.85 & 0.83 \\
Dominance (D) & 0.0261 & 0.0479 & 0.0474 & 0.0529 \\
\hline
\end{tabular}

Table 6: Pairwise comparison of the avifaunal assemblages in the four study sites using Sørensen similarity coefficient

\begin{tabular}{lcccr}
\hline & Natural & Tea & Rubber & Oil palm \\
\hline Natural & & & & \\
Tea & 0.8000 & & & \\
Rubber & 0.7625 & 0.9466 & & \\
Oil palm & 0.6887 & 0.8871 & 0.9076 & \\
\hline
\end{tabular}

\section{Mammalian assemblage}

A total of 35 species of mammals were observed during the study period. This included 7 species of endemic mammals and 8 species of threatened mammals (Table 7). The highest species richness (30 species) was observed in the natural forest, which included all the endemic and threatened species recorded. Further, 5 out of the 7 endemic species and 7 out of the 8 threatened species were found to be restricted to the natural forest. Among the agro-ecosystems the highest species richness was recorded in the tea plantations ( 23 species) followed by plantations of oil palm and rubber (22 species each).

Table 7: Summary of mammals recorded at the four sites. The number in parenthesis indicates the number of species restricted to that particular habitat

\begin{tabular}{lccccc}
\hline Category & Total & Natural & Tea & Rubber & Oil palm \\
\hline Number of species & 35 & $30(12)$ & 23 & 22 & 22 \\
Endemic species & 7 & $7(5)$ & 2 & 1 & 1 \\
Threatened species & 8 & $8(7)$ & 1 & 1 & 1 \\
\hline
\end{tabular}

Table 8: Species diversity, evenness, and dominance indices of the mammals in the four study sites

\begin{tabular}{|c|c|c|c|c|}
\hline & \multicolumn{4}{|c|}{ Vegetation types } \\
\hline & Natural & Tea & Rubber & Oil palm \\
\hline \multicolumn{5}{|l|}{ Diurnal mammals } \\
\hline \multicolumn{5}{|l|}{ Shannon-wiener } \\
\hline diversity index (H') & 1.3955 & 1.1193 & 0.8806 & 0.9158 \\
\hline Evenness (E) & 0.72 & 0.70 & 0.64 & 0.66 \\
\hline Dominance (D) & 0.2978 & 0.4349 & 0.5337 & 0.5249 \\
\hline \multicolumn{5}{|l|}{ Nocturnal mammals } \\
\hline Shannon-wiener & & & & \\
\hline diversity index (H') & 1.6206 & 0.2081 & 0.3046 & 0.8037 \\
\hline Evenness (E) & 0.90 & 0.30 & 0.44 & 0.73 \\
\hline Dominance (D) & 0.2302 & 0.7351 & 0.8347 & 0.5433 \\
\hline
\end{tabular}

Table 9: Pair wise comparison of the mammalian assemblages in the four study sites using Sørensen similarity coefficient

\begin{tabular}{lllll}
\hline & Natural & Tea & Rubber & Oil palm \\
\hline Natural & & & & \\
Tea & 0.7737 & & & \\
Rubber & 0.6792 & 0.9778 & & \\
Oil Palm & 0.6538 & 0.9545 & 0.9767 & \\
\hline
\end{tabular}


The diversity, dominance, and evenness were calculated separately for the nocturnal and diurnal mammals as the sampling effort and sampling method varied for these two conditions. During daytime more mammals were observed in the natural vegetation than in the plantations. Among the plantations, the oil palm plantation had the highest observed number of animals during the study period.

The natural forest had a higher species diversity followed by tea, oil palm and rubber for diurnal mammals while among the nocturnal mammals the highest diversity in agro-ecosystems was observed in the oil palm followed by rubber and tea (Table 8 ). The evenness (E) was relatively low especially for agro-ecosystems indicating that species assemblages were dominated by a few species. This is further confirmed by high values obtained for $\mathrm{D}$. The individual density data shows that species assemblage is dominated by 3 species, namely, Funambulus palmarum (Palm squirrel), Herpestes brachyurus (Brown mongoose) and Semnopithecus vetulus (Purple faced leaf monkey).

A pairwise comparison of the mammalian assemblages between each study site showed that there is a higher degree of similarity among the 3 agroecosystems while the natural forest showed a low level of similarity to any of the 3 agro-ecosystems (Table 9).

The highest density of mammals was recorded in the natural forest compared to the agro-ecosystems. In the natural forest Macaca sinica (0.878 animals/ ha) and Trachypithecus vetulus (0.766 animals/ ha) were the most abundant species of mammals.

\section{Overall assemblage of vertebrate fauna}

In the course of this study 187 species of vertebrates belonging to 58 families were observed. The natural forest had the highest vertebrate richness (178 species) compared to the man-made plantations where rubber had the highest richness (117 species) followed by the tea (113 species) and oil palm (109 species). Furthermore, the natural forest supported a high number of endemic species (41). In the man-made vegetation rubber plantations had the highest number of endemic species (14) followed by oil palm (13 species) and tea (10 species). The highest diversity was recorded in the natural forest (4.3774) while in the man-made habitats oil palm had the highest diversity value (3.9324) followed by rubber (3.9274) and tea (3.7921). E was relatively high in all 4 sites indicating that no specific species dominated the species assemblage. This is further confirmed by low values obtained for $\mathrm{D}$.

\section{DISCUSSION}

The results of this study indicate that the natural ecosystem had the highest species richness, diversity, density and endemicity for all three faunal groups studied, compared to the plantations. When considering the herpetofauna, the species assemblage in the agroecosystems was dominated by a few species while rare species were absent or represented by few individuals. Heinen (1992), reports that both evenness and richness of herpetofauna decline with disturbance and generally a few species dominate the species assemblage in such disturbed ecosystems. Results of this study are consistent with this observation. Species assemblage found in the natural forest is dominated by threatened, rare and endemic species indicating the significance of natural habitats for species survival. Common species such as Calotes calotes, C. versicolor, and Bufo melanostictus were recorded in all four study sites. However, their density was higher in agro-ecosystems compared to the natural forest. Therefore, the species assemblage in

Table 10: A summary of species richness, diversity, evenness, dominance, endemism and conservation status of the total vertebrate assemblage in the four study sites

\begin{tabular}{lllll}
\hline & \multicolumn{4}{c}{ Vegetation types } \\
& Natural & Tea & Rubber & Oil palm \\
\hline Richness (no. of species) & 178 & 113 & 117 & 109 \\
Number of endemic species & $41(25)$ & 10 & 14 & 13 \\
No. of nationally threatened species & $18(14)$ & 4 & 3 & 3 \\
Shannon-wiener diversity index (H') & 4.3774 & 3.7921 & 3.9274 & 3.9324 \\
Evenness (E) & 0.8439 & 0.8068 & 0.8175 & 0.8399 \\
Dominance (D) & 0.0014 & 0.0349 & 0.0302 & 0.0294 \\
\hline
\end{tabular}

Note: The number in parenthesis indicates the number of species restricted to that particular habitat. 
man-made ecosystems, even though low in endemic, threatened and rare species, plays an important role in maintenance of common species.

The high density of herpetofauna in the natural forest can be attributed to high microhabitat diversity and abundance of prey species such as arthropods in the natural forest compared to the agro-ecosystems. Among the three agro-ecosystems, microhabitat availability and abundance of food was found to be highest in the rubber plantation followed by oil palm and tea, and the results were consistent with this pattern. The lowest diversity and density was recorded in the tea plantation. Tea cultivated lands had high light intensity, less leaf litter depth and less canopy cover compared to other three habitats. These conditions result in high ambient temperature and low humidity, which could be the reason for low density and diversity of herpetofauna observed.

Among the birds, few species were found to be dominating the species assemblage while most species were rare or represented by a few individuals. In the agro-ecosystems evenness and dominance indices indicate that this phenomenon is much more pronounced in the oil palm plantations, compared to the rubber and tea plantations. This pattern is exactly the reverse of what was observed for herpetofauna. This can be attributed to the fact that substrate availability and canopy structure is least diverse in the oil palm compared to the rubber and tea plantations. As different species of birds use different niches, the tea plantation that supported a wide variety of niches than the other two agro-ecosystems supported a high diversity and density of birds.

Of the bird species recorded in this study 29 species $(30 \%)$ were found only in the natural forest. Furthermore, eight endemic species, most of them recorded only on a few occasions were also restricted to the natural forest. Endemism in agro-ecosystems is low compared to the natural forest. Observations on nesting also indicate that endemic birds prefer natural forest as nesting sites. These results illustrate the potential importance of natural vegetation as a refuge for rare endemic bird species. However, the man-made ecosystems support a large number of bird species and therefore serve as valuable bird habitats.

The Dollar bird (Eurystomus orientalis), a threatened species was recorded in the natural forest and tea plantations during this study. This is the first time that this species has been recorded in this area. According to the habitat description of the Dollar bird it prefers dense forest and rarely visits open areas. The bird observed in the tea plantation might have come from the natural forest as the tea plantation is located close to a natural forest $(1.5 \mathrm{~km})$.

Physiognomy of the vegetation is an important determinant of distributions and densities of mammals (Karunaratne \& Wickramanayake, 1990). The highest species richness, diversity and abundance of mammals was observed in the natural forest. This could be attributed to the high structural and habitat complexity of low land rainforests compared to the three agro-ecosystems. This pattern could also be seen among the three agroecosystems where the tea plantation, which had the highest structural and habitat complexity, also had the highest species richness. However, the oil palm plantation had the highest mammalian abundance compared to the other three plantations. This could be attributed to the presence of high numbers of Funambulus palmarum in the oil palm plantation during daytime and Viverricula indica at night, due to abundance of food for these two species. $V$. indica mainly feeds on rodents, especially Rattus rattus kandianus, which is a pest species found in oil palm plantations. Therefore, $V$. indica acts as a biological pest controlling agent in oil palm plantations.

The findings of this study clearly highlight the importance of natural vegetation for preservation of indigenous and endemic faunal assemblages. However, this study also proves the value of man-made ecosystems as habitats for large number of species. Therefore, for effective biodiversity conservation, one should focus not only on conservation of natural habitats but should also promote such agricultural and forestry practices that are favourable for biodiversity conservation as these can be used as important links between isolated forest patches. If properly managed these faunal assemblages in man-made ecosystems will contribute to enhanced productivity while helping biodiversity conservation.

\section{Acknowledgement}

The authors acknowledge Thilak and Kapila for the assistance provided in the field and the Department of Forest Conservation for granting permission to conduct this study. The National Science Foundation is also acknowledged for providing financial support for this project (Grant no. NSF/RSP/UOR/A/02/2001).

\section{REFERENCES}

1. Bambaradeniya C.N.B., Edirisingha J.P., De Silva D.N., Gunathileke C.V.S., Ranawana K.B. \& Wijekoon S. (2004). Biodiversity associated with an irrigated rice agroecosystem in Sri Lanka. Biodiversity and Conservation 13: $1715-1753$ 
2. Bambaradeniya C.N.B. (2006). Fauna of Sri Lanka: Status of Taxonomy, Research \& Conservation, pp.308. International Union for Conservation of Nature, Colombo \& Government of Sri Lanka.

3. Brookes T.M., Mittermeier R.A., Mittermeier C.G., Fonseca G.A.B. da, Rylands A.B., Konstant W.R., Flick P., Pilgrim J., Oldfield S., Magin G. \& Hilton-Taylor C. (2002). Habitat loss and extinction in the hotspots of biodiversity. Conservation Biology 16: 909-923.

4. Corbet G.B. \& Hill J.E. (1992). Mammals of the Indomalayan Region: A Systematic Review, p. 488. Oxford University Press, Oxford, UK.

5. Das I. \& de Silva A. (2005). A Photographic Guide to Snakes and Other Reptiles of Sri Lanka. pp. 144. New Holland Publishers Ltd., London, UK.

6. Dutta S.K. \& Manamendra-Arachchi K. (1996). The Amphibian Fauna of Sri Lanka, p.280. Wildlife Heritage Trust of Sri Lanka, 95, Cotta Road, Colombo 8.

7. Gamage S.N. \& Weerakoon D.K. (2007). Vertebrate diversity in a 30 year old regenerated forest with special reference to avifauna. Siyoth 2 (1) 17-21.

8. Gamage S.N., Liyanage W.K.D.D., Wimalasuriya S. \& Gunawardena A. (2007). Vertebrates diversity in the 30 years of old analogue forest in Pitigala, Elpitiya, in the Galle district of southern Sri Lanka. Ruhuna Journal of Science 1: 158-173.

9. Harrison J. (1999). A Field Guide to the Birds of Sri Lanka, p. 219. Oxford University Press, Oxford, UK.

10. Heinen J.H. (1992). Comparisons of the leaf litter herpetofauna in abandoned cacao plantations and primary rain forest in Costa Rica: some implications for faunal restoration. Biotropica 24(3): 431-439.

11. IUCN (2010). The Red List of Threatened Species. www. iucn.redlist.org. Accessed in December 2006.

12. IUCN Sri Lanka and the Ministry of Environment and Natural Resources (2007). The 2007 Red List of Threatened Fauna and Flora of Sri Lanka, pp.148. Colombo.

13. Karunarathna P.B. \& Wikramanayake E.D. (1990) Habitat preferences of small mammals in Udawalawe National Park. Special Scientific Publication Series of the Wildlife and Nature Protection Society of Sri Lanka 1(1): 3-16.
14. Magurran A. (1988). Ecological diversity and its measurement, p. 192. Princeton University Press, Princeton, New Jersey, USA.

15. Manamendra-Arachchi K. \& Pethiyagoda R. (1998). A synopsis of the Sri Lankan Bufonidae (Amphibia: Anura) with description of new species. Journal of South Asian Natural History 3: 213-248.

16. Manamendra-Arachchi K. \& Pethiyagoda R. (2005). A Sri Lankan shrub-frogs of the genus Philautus Istel, 1848 (Ranidae: Rhacophorinae), with description of 27 new species. Raffles Bulletin of Zoology. 12: 163-303.

17. McNeely J.A. (1995). How traditional agro-ecosystems can contribute to conserving biodiversity. Conserving Biodiversity Outside Protected Areas: The Role of Traditional Agro-ecosystems (eds. P. Halladay \& D.A. Gilmour), pp. 20-40. International Union for Conservation of Nature, Gland, Switzerland and Cambridge, UK.

18. Meegaskumbura M. \& Manamendra-Arachchi K. (2005). Description of eight new species of shrub frogs (Ranidae: Rhacophorinae, Philautus) from Sri Lanka. Raffles Bulletin of Zoology 12: 163-303.

19. Mittermeier R.A., Gil P.R., Hoffman M., Pilgrim J., Brooks T., Mittermeier C.G., Lamoreux J. \& da Fonseca G.A.B. (2005). Hotspots Revisited: Earth's Biologically Richest and Most Threatened Ecoregions, pp. 392. Conservation International, Washington DC, USA.

20. Myers N., Mittermeier R.A., Mittermeier C.G., da Fonseca G.A.B. \& Kent J. (2000). Biodiversity hot spots for Conservation Priorities. Nature. 403: 853-858.

21. Pethiyagoda R. \& Manamendra-Arachchi K. (1998). A revision of the endemic Sri Lankan agamid lizard genus Ceratophora Gray, 1835, with description of two new species. Journal of South Asian Natural History 3(1): $1-50$.

22. Scherr S.J. \& Shames S. (2006). Agriculture: a threat or promise for biodiversity conservation. Arborvitae. The IUCN/WWF Forest Conservation Newsletter.

23. Southwood T.R.E. \& Henderson P.A. (2000). Ecological Methods, $3^{\text {rd }}$ edition, p. 575. Wiley-Blackwell, Oxford, UK.

24. Wickramasinghe M. \& Somaweera R. (2003). Distribution and current status of the endemic geckos of Sri Lanka. Gekko 3(1): 3-13. 